\title{
Effects of whole-body vibration exercise on functions required for bowling performance of male bowling player
}

\author{
Jun-Su Kim* \\ Department of Kinesiology, Inha University, Incheon, Korea
}

The focus of this research is to examine the impact of 8 weeks of whole body vibration (WBV) exercise on physical factors by conducting an experiment on 17 male bowling players registered in Korea Bowling Association. Strength of truncus and lower-limb and balance were measured as the physical factors and the impact of WBV exercise on each variable was examined. There was significant increase between groups in flexor-weight ratio of truncus at $60 \% \mathrm{sec}$ according to performance after applying WBV exercise. There was significant difference in groups before bowling event in pre and posttest as well as after bowling event in pre and posttest. There was significant difference of extensor-weight ratio in groups after bowling event in pre and posttest. There was significant increase at $60 \% \mathrm{sec}$ in flexor-ratio of both left and right lower-limb strength according to performance after applying WBV exercise. There was significant difference between groups before bowling event in pre and posttest as well as after bowling event in pre and posttest. Extensor-weight ratio showed significant difference between groups only before bowling event in pre and posttest. There was significant difference between groups in both left and right balance according to performance after applying WBV exercise. There was significant difference in before bowling event in pre and posttest as well as after bowling event in pre and posttest.

Keywords: Bowling, Whole-body vibration exercise, Cybex, Balance

\section{INTRODUCTION}

Bowling requires consideration of the player's own physical characteristics and techniques within the environment of bowling arena as well as independent space (lane, approach) and choice of balls to function efficiently in accordance with the lane condition. Therefore, it is required for a bowling player to seek for harmony among his or her environmental adaptation, techniques and physical characteristics and also high level of concentration.

Wirth et al. (2011) stated that reinforced lower-limb strength serves an important function by effectively controlling the center of gravity. In addition, bowling is a unilateral exercise which requires throwing a heavy ball strongly and maintaining the accurate finish posture after a series of movements. The last finish posture is a phase to reduce the momentum by smooth sliding which gives increased pressure on waist, knees and shoulders. Excessive force may be applied during the back swing so it could cause

physical imbalance followed by reduction of harmonized movement by upper and lower part of the body. Therefore, proper operation and movement of the core muscles composed of a bowling player's spine, pelvis, buttocks and abdomen reduce distortion of shoulders and waist while creating harmonized movement of upper and lower body, which in turn enables effective bowling movement and prevents injuries during the training and games (Krabak and Kennedy, 2008; Verhagen et al., 2004).

Eventually, a successful movement of a bowling player requires not only technical movements but also scientific and efficient training to improve physical functions. Among the previous research focusing on reinforcing bowling players' strength of upper and lower-limb, there is a dearth of studies on effective training considering the physical factors of bowling players. In particular, there is no research on training programs to strengthen core muscles to improve body balance. In this sense, an effective training program is required to improve athletic performance by reinforc-

${ }^{*}$ Corresponding author: Jun-Su Kim (iD https://orcid.org/0000-0002-7078-4926 Department of Kinesiology, Inha University, 100 Inha-ro, Nam-gu, Incheon 22212, Korea 
ing core muscles and lower-limb strength.

Recently, muscular function training using whole body vibration (WBV) exercise is being widely used as the exercise equipment to reinforce the lower-limb strength and body balance (Jepsen et al., 2017). WBV exercise is safe, convenient and brings diverse physical effects such as in musculoskeletal system, circulatory system and endocrine system. It gives a new type of stimulation to the human body through rapid and strong muscle contraction by artificially adjusting the gravitational load on the body. There is no risk factor in WBV unlike other resistance exercises which may cause sports injuries by giving excessive stimulations on the human body followed by lifting heavy weights. WBV exercise improves muscular functions by controlling the weight to avoid excessive pressure on the body.

Among the previous literature on WBV, Bosco et al. (1999) reported that effects of WBV in reinforcing the lower-limb strength are identical to those of leg-press exercise by studying six female volleyball players. Delecluse et al. (2003) reported improvement of static and dynamic muscular strength by conducting 12 weeks of weight training and WBV exercise after dividing 67 females without prior exercise experience into two groups. In particular, they reported that the group applied with WBV exercise demonstrated higher muscular power. Abercromby et al. (2007) reported significantly increased muscular strength in vastus lateralis, bicephalus femoris, gastrocnemius and anterior tibial muscle as a result of conducting WBV exercise to 16 healthy adults. These previous studies are limited to the research conducted to ordinary people to see if WBV exercise is effective in improving body composition and muscle strength. On the contrary, there has been no research that examined the impact of WBV exercise on bowling players' lower-limb strength and core muscles to improve their athletic performance. Therefore, this research aims to analyze and investigate the impact of WBV exercise on bowling players' lower-limb strength and core muscles to improve their athletic performance as well as suggest effective training programs for better performance.

\section{MATERIALS AND METHODS}

\section{Research subjects}

The subjects of this research are 20 bowling players registered in Korea Bowling Association and they were randomly divided into 10 players applied with WBV exercise and 10 players as the control group. During the experimentation, two players were injured and one player was dropped out so the experiment was con-
Table 1. Characteristic of subjects

\begin{tabular}{lcc}
\hline Characteristic & WVG & CG \\
\hline Age $(\mathrm{yr})$ & $26.56 \pm 4.93$ & $23.78 \pm 3.60$ \\
Height $(\mathrm{cm})$ & $177.70 \pm 4.60$ & $179.19 \pm 5.06$ \\
Weight $(\mathrm{kg})$ & $71.76 \pm 5.97$ & $84.43 \pm 16.19$ \\
Body mass index $\left(\mathrm{kg} / \mathrm{m}^{2}\right)$ & $23.06 \pm 2.28$ & $26.24 \pm 4.57$ \\
\hline
\end{tabular}

Values are presented as mean \pm standard deviation.

WVG, whole body vibration group; CG, control group.

ducted to 17 players of which WBV group consisted of eight players and control group consisted of nine players. The research subjects satisfied following criteria and they were explained with the research contents and objective, experimental process, human rights protection of the subjects and all information related to the research. They all understood the intention of this research and voluntarily agreed to the participation. Table 1 demonstrates the characteristics of the subjects. Following criteria were applied: Bowling players with more than five years of experience who are registered in Korea Bowling Association. Players with average score of above 200. Players with no health problems in cardiovascular system, respiratory system and orthopedics.

\section{Research process}

In this research, 17 male bowling players (eight players in experimental and nine players in control group) who are registered in Korea Bowling Association were applied with 8 weeks of WBV exercise before playing six bowling events. The research was designed to examine the impact of WBV exercise on factors which affect bowling performance such as truncus, lower-limb strength and balance, before and after the experiment (Fig. 1).

\section{Statistical analysis}

The research data were analyzed using IBM SPSS Statistics ver. 22.0 (IBM Co., Armonk, NY, USA). An independent $t$-test was conducted for homogeneity check of variables by each group. As a result of the homogeneity check, the part of homogeneity of measured variables was not confirmed thus analysis of covariance (ANCOVA) was conducted by designating variables measured before the bowling event during the pretest as covariates. Repeated measured analysis of variance (ANOVA) was conducted to verify the effects of variables between the groups based on the estimates of ANCOVA. The level of significance $(\alpha)$ was set at 0.05 for all statistical analysis. 


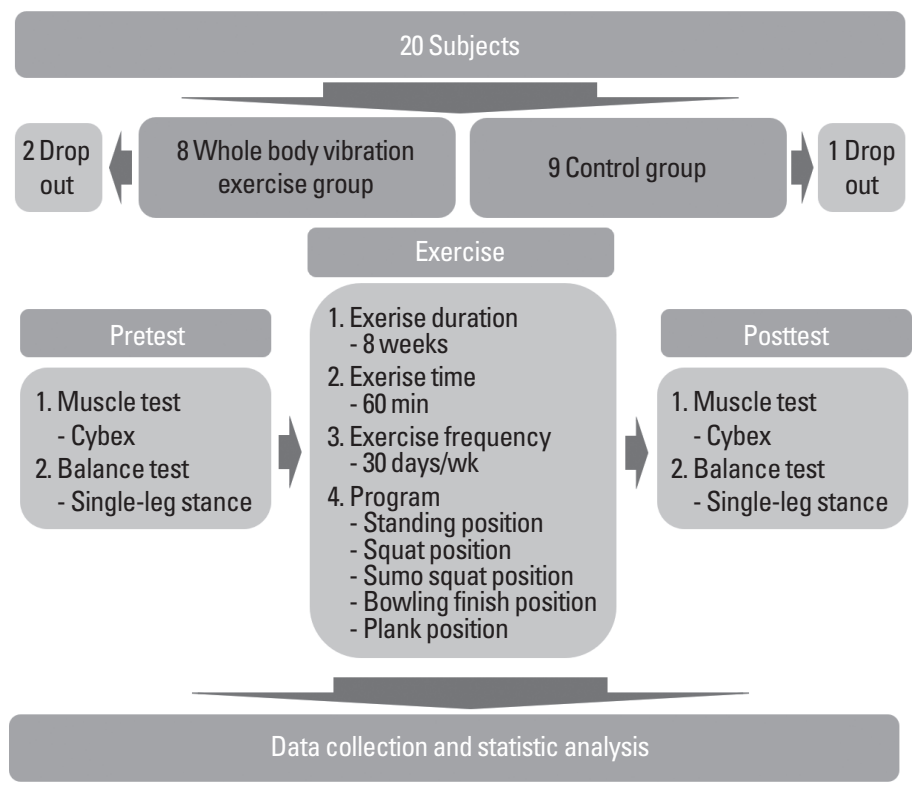

Fig. 1. Schematic diagram of study process.

Table 2. The change of flexor and extensor peak torque at descriptive statistics estimate of covariate (unit: $\mathrm{Nm} / \mathrm{kg}$ )

\begin{tabular}{|c|c|c|c|c|c|c|c|c|}
\hline \multirow{2}{*}{ Variable } & \multicolumn{4}{|c|}{$W V G(n=8)$} & \multicolumn{4}{|c|}{$C G(n=9)$} \\
\hline & Pre-pre & Pre-post & Post-pre & Post-post & Pre-pre & Pre-post & Post-pre & Post-post \\
\hline Flexor & $196.3 \pm 44.3$ & $184.3 \pm 28.2$ & $237.1 \pm 57.7$ & $212.1 \pm 46.8$ & $221.2 \pm 43.4$ & $198.4 \pm 36.6$ & $212.7 \pm 36.6$ & $179.3 \pm 54.3$ \\
\hline Extensor & $368.7 \pm 34.9$ & $352.1 \pm 47.5$ & $423.4 \pm 74.1$ & $419.9 \pm 94.3$ & $362.3 \pm 63.1$ & $373.0 \pm 66.7$ & $357.4 \pm 82.8$ & $325.3 \pm 50.7$ \\
\hline
\end{tabular}

Values are presented as mean \pm standard deviation.

WVG, whole body vibration group; $\mathrm{CG}$, control group.

Pre-pre, pre-test before bowling game; Pre-post, pre-test after bowling game; Post-pre, post-test before bowling game; Post-post, pre-test after bowling game.

\section{RESULTS}

\section{Changes in maximum rotatory force of flexor and extensor in truncus}

Among the measured variables of each group, Table 2 demonstrates the descriptive statistics regarding the maximum rotatory force of flexor and extensor in truncus by each period.

In the pretest regarding maximum rotatory force of flexor, the WBV group showed $196.3 \pm 44.3$ before the bowling event and $184.3 \pm 28.2$ after the bowling event, whereas the control group showed 221.2 \pm 43.4 before the bowling event which was reduced to $198.4 \pm 36.6$ after the bowling event. In the posttest, the WBV group showed 237.1 \pm 57.7 before the bowling event and 212.1 \pm 46.8 after the bowling event, whereas the control group showed $212.7 \pm 36.6$ before the bowling event which was reduced to $179.3 \pm 54.3$ after the bowling event.

In the pretest regarding maximum rotatory force of extensor, the WBV group showed $368.7 \pm 34.9$ before the bowling event and $352.1 \pm 47.5$ after the bowling event, whereas the control group showed $362.3 \pm 63.1$ before the bowling event which was increased to $373.0 \pm 66.7$ after the bowling event. In the posttest, the WBV group showed $423.4 \pm 74.1$ before the bowling event and $419.9 \pm 94.3$ after the bowling event, whereas the control group showed $357.4 \pm 82.8$ before the bowling event which was reduced to $325.3 \pm 50.7$ after the bowling event.

Table 3 demonstrates the result of repeated measured ANOVA to examine the changes in maximum rotatory force of flexor and extensor in truncus.

The results of repeated measured ANOVA showed that the changes were not significant for flexor, which was significant in terms of measurement timing and interactions $(F=5.56, P<0.01$; $F=4.93, P<0.01)$. As a result of individual comparison, there was significant difference between before the bowling event during the pretest and before the bowling event during the posttest as well as after the bowling event during the pretest and after the bowling event during the posttest $(F=7.14, P<0.05 ; F=6.24$, 
Kim JS • Whole-body vibration exercise on bowling performance

Table 3. The difference of flexor and extensor peak torque between groups tested by repeated measured analysis of variance

\begin{tabular}{|c|c|c|c|c|c|c|c|c|}
\hline Source & & & & SS & DF & MS & $F$ & $P$-value \\
\hline \multirow[t]{9}{*}{ Flexor } & Within & Time & & $12,013.37$ & 3 & $4,004.45$ & 5.56 & $0.002^{* *}$ \\
\hline & & Time $\times$ group & & $10,669.04$ & 3 & $3,556.34$ & 4.93 & $0.005^{* *}$ \\
\hline & & Error & & $34,559.33$ & 48 & 719.98 & & \\
\hline & Between & Group & & 103.92 & 1 & 103.92 & 0.07 & 0.791 \\
\hline & & Error & & $36,407.64$ & 15 & $2,427.17$ & & \\
\hline & Contrast & Time $\times$ group & $1: 2$ & 624.22 & 1 & 624.22 & 0.46 & 0.503 \\
\hline & & & $1: 3$ & $10,952.00$ & 1 & $10,952.00$ & 7.14 & $0.017^{*}$ \\
\hline & & & $2: 4$ & $9,476.05$ & 1 & $9,476.05$ & 6.24 & $0.024^{*}$ \\
\hline & & & $3: 4$ & 312.50 & 1 & 312.50 & 0.21 & 0.652 \\
\hline \multirow[t]{9}{*}{ Extensor } & Within & Time & & $8,452.77$ & 3 & $2,817.59$ & 1.03 & 0.384 \\
\hline & & Time $\times$ group & & $37,998.94$ & 3 & $12,666.31$ & 4.66 & $0.006^{* *}$ \\
\hline & & Error & & $130,352.27$ & 48 & $2,715.67$ & & \\
\hline & Between & Group & & $5,995.12$ & 1 & $5,995.12$ & 2.47 & 0.136 \\
\hline & & Error & & $36,407.64$ & 15 & $2,427.17$ & & \\
\hline & Contrast & Time $\times$ group & $1: 2$ & 156.05 & 1 & 156.05 & 0.04 & 0.844 \\
\hline & & & $1: 3$ & $11,200.05$ & 1 & $11,200.05$ & 1.72 & 0.208 \\
\hline & & & $2: 4$ & $59,973.38$ & 1 & $59,973.38$ & 11.93 & $0.003^{* *}$ \\
\hline & & & $3: 4$ & 3,669.38 & 1 & $3,669.38$ & 0.61 & 0.446 \\
\hline
\end{tabular}

SS, sum of squares; DF, degree of freedom; MS, mean of squares.

1, pre-pre: pre-test before bowling game; 2, pre-post: pre-test after bowling game; 3, post-pre: post-test before bowling game; 4, post-post: post-test after bowling game. ${ }^{*} P<0.05$. ${ }^{*} P<0.01$.

Table 4. The change of flexor and extensor peak torque at descriptive statistics and estimate of covariate (unit: $\mathrm{Nm} / \mathrm{kg}$ )

\begin{tabular}{|c|c|c|c|c|c|c|c|c|}
\hline \multirow{2}{*}{ Variable } & \multicolumn{4}{|c|}{ WVG $(n=8)$} & \multicolumn{4}{|c|}{$\mathrm{CG}(\mathrm{n}=9)$} \\
\hline & Pre-pre & Pre-post & Post-pre & Post-post & Pre-pre & Pre-post & Post-pre & Post-post \\
\hline \multicolumn{9}{|l|}{ Flexor } \\
\hline Right & $115.44 \pm 22.16$ & $107.78 \pm 26.06$ & $141.67 \pm 23.00$ & $134.00 \pm 20.35$ & $132.00 \pm 23.04$ & $122.67 \pm 21.31$ & $120.33 \pm 24.01$ & $108.56 \pm 26.29$ \\
\hline Left & $112.89 \pm 34.68$ & $107.56 \pm 41.05$ & $141.00 \pm 33.81$ & $136.00 \pm 34.17$ & $122.67 \pm 23.61$ & $114.44 \pm 23.89$ & $116.67 \pm 21.78$ & $108.78 \pm 23.51$ \\
\hline \multicolumn{9}{|l|}{ Extensor } \\
\hline Right & $217.67 \pm 55.13$ & $216.44 \pm 52.65$ & $256.78 \pm 54.50$ & $243.44 \pm 60.07$ & $245.44 \pm 50.78$ & $230.00 \pm 45.91$ & $214.00 \pm 26.00$ & $205.11 \pm 49.43$ \\
\hline Left & $220.33 \pm 69.18$ & $217.89 \pm 67.52$ & $261.39 \pm 43.37$ & $243.33 \pm 41.65$ & $235.67 \pm 59.45$ & $222.22 \pm 33.08$ & $212.67 \pm 37.64$ & $199.11 \pm 43.43$ \\
\hline
\end{tabular}

Values are presented as mean \pm standard deviation.

WVG, whole body vibration group; CG, control group.

Pre-pre, pre-test before bowling game; Pre-post, pre-test after bowling game; Post-pre, post-test before bowling game; Post-post, pre-test after bowling game.

$P<0.01)$.

The extensor did not show significant difference in terms of main effects between the groups and measurement timing but showed significant difference in the interactions $(F=4.66, P<0.01)$. As a result of individual comparison, there was significant difference only between after the bowling event during the pretest and after the bowling event during the posttest $(F=11.93, P<0.01)$.

\section{Changes in maximum rotatory force of flexor and extensor in lower-limb}

Table 4 demonstrates the descriptive statistics regarding the maximum rotatory force of flexor in lower-limb by each period.

In the pretest of right lower-limb's muscular strength, the WBV group showed $115.44 \pm 22.16$ before the bowling event and $107.78 \pm 26.06$ after the bowling event whereas the control group showed $132.00 \pm 23.04$ before the bowling event which was reduced to $122.67 \pm 21.31$ after the bowling event. In the posttest, the WBV group showed $141.67 \pm 23.00$ before the bowling event and $134.00 \pm 20.35$ after the bowling event whereas the control group showed $120.33 \pm 24.01$ before the bowling event which was reduced to $108.56 \pm 26.29$ after the bowling event. 
In the pretest of left lower-limb's muscular strength, the WBV group showed $112.89 \pm 34.68$ before the bowling event and $107.56 \pm 41.05$ after the bowling event whereas the control group showed $122.67 \pm 23.61$ before the bowling event which was reduced to $114.44 \pm 23.89$ after the bowling event. In the posttest, the WBV group showed $141.00 \pm 33.81$ before the bowling event and $136.00 \pm 34.17$ after the bowling event whereas the control group showed $116.67 \pm 21.78$ before the bowling event which was reduced to $108.78 \pm 23.51$ after the bowling event.

In the pretest of right side extensor-weight ratio, the WBV group showed $217.67 \pm 55.13$ before the bowling event and $216.44 \pm 52.65$ after the bowling event whereas the control group showed $245.44 \pm 50.78$ before the bowling event which was reduced to $230.00 \pm 45.91$ after the bowling event. In the posttest, the WBV group showed 256.78 \pm 54.50 before the bowling event and $243.44 \pm 60.07$ after the bowling event whereas the control group showed $214.00 \pm 26.00$ before the bowling event which was reduced to $205.11 \pm 49.43$ after the bowling event.

In the pretest of left side extensor-weight ratio, the WBV group showed $220.33 \pm 69.18$ before the bowling event and $217.89 \pm 67.52$ after the bowling event whereas the control group showed $245.44 \pm 50.78$ before the bowling event which was reduced to $230.00 \pm 45.91$ after the bowling event. In the posttest, the WBV group showed $261.89 \pm 43.37$ before the bowling event and $243.33 \pm 41.65$ after the bowling event whereas the control group showed $212.67 \pm 37.64$ before the bowling event which was reduced to $199.11 \pm 48.43$ after the bowling event.

Table 5 demonstrates the result of repeated measured ANOVA to examine the changes in maximum rotatory force of flexor in lower-limb.

The results of repeated measured ANOVA for right lower-limb's muscular strength showed significant difference in measurement timing and interactions $(F=10.93, P<0.001)$ whereas there was no significant difference in the main effect. As a result of individual comparison, there was significant difference between before the bowling event during the pretest and before the bowling event during the posttest as well as after the bowling event during the pretest and after the bowling event during the posttest $(F=14.37, P<0.01 ; F=12.91, P<0.01)$.

The results of repeated measured ANOVA for left lower-limb's muscular strength showed significant difference in measurement timing and interactions whereas there was no significant difference in the main effect $(F=4.84, P<0.01 ; F=8.35, P<0.001)$. As a result of individual comparison, there was significant difference between before the bowling event during the pretest and before the bowling event during the posttest as well as after the

Table 5. The difference of flexor peak torque between groups tested by repeated measured analysis of variance

\begin{tabular}{|c|c|c|c|c|c|c|c|c|}
\hline Source & & & & SS & DF & MS & $F$ & $P$-value \\
\hline \multirow[t]{9}{*}{ Right } & Within & Time & & $2,300.94$ & 3 & 766.98 & 3.63 & $0.019^{*}$ \\
\hline & & Time $\times$ group & & $6,927.83$ & 3 & $2,309.27$ & 10.93 & $0.000^{* * *}$ \\
\hline & & Error & & $10,141.72$ & 48 & 211.28 & - & - \\
\hline & Between & Group & & 66.12 & 1 & 66.12 & 0.17 & 0.685 \\
\hline & & Error & & $5,800.43$ & 15 & 286.69 & - & - \\
\hline & Contrast & Time x Group & $1: 2$ & 12.50 & 1 & 12.50 & 0.03 & 0.865 \\
\hline & & & $1: 3$ & $6,460.05$ & 1 & $6,460.05$ & 14.37 & $0.002^{* *}$ \\
\hline & & & $2: 4$ & $7,320.50$ & 1 & $7,320.50$ & 12.91 & $0.002^{* *}$ \\
\hline & & & $3: 4$ & 76.05 & 1 & 76.05 & 0.30 & 0.592 \\
\hline \multirow[t]{9}{*}{ Left } & Within & Time & & $3,054.11$ & 3 & $1,018.03$ & 4.84 & $0.005^{* *}$ \\
\hline & & Time $\times$ group & & $5,273.61$ & 3 & $1,757.87$ & 8.35 & $0.000^{* * *}$ \\
\hline & & Error & & $10,097.27$ & 48 & 210.36 & - & - \\
\hline & Between & Group & & 342.34 & 1 & 342.34 & 0.45 & 0.512 \\
\hline & & Error & & $11,411.56$ & 15 & 760.77 & - & - \\
\hline & Contrast & Time $\times$ group & $1: 2$ & 37.55 & 1 & 37.55 & 0.13 & 0.714 \\
\hline & & & $1: 3$ & $5,236.05$ & 1 & $5,236.05$ & 11.11 & $0.004^{* *}$ \\
\hline & & & $2: 4$ & $5,236.05$ & 1 & $5,236.05$ & 9.41 & $0.007^{* *}$ \\
\hline & & & $3: 4$ & 37.55 & 1 & 37.55 & 0.10 & 0.748 \\
\hline
\end{tabular}

SS, sum of squares; DF, degree of freedom; MS, mean of squares.

1, pre-pre: pre-test before bowling game; 2, pre-post: pre-test after bowling game; 3, post-pre: post-test before bowling game; 4, post-post: post-test after bowling game. ${ }^{*} P<0.05$. ${ }^{* *} P<0.01 .{ }^{* * *} P<0.001$. 
bowling event during the pretest and after the bowling event during the posttest $(F=11.11, P<0.01 ; F=9.41, P<0.01)$.

Table 6 demonstrates the result of repeated measured ANOVA to examine the changes in maximum rotatory force of extensor.

The results of repeated measured ANOVA for maximum rotatory force of right side extensor showed significant difference in the interactions $(F=5.03, P<0.001)$ whereas there was no significant difference in the main effect. As a result of individual comparison, there was significant difference between before the bowling event during the pretest and before the bowling event during the posttest $(F=12.05, P<0.001)$.

The results of repeated measured ANOVA for maximum rotatory force of left side extensor, there was significant difference in the interactions $(F=4.87, P<0.01)$ whereas there was no significant difference in the main effect. As a result of individual com- parison, there was significant difference between before the bowling event during the pretest and before the bowling event during the posttest $(F=8.60, P<0.05)$.

\section{Changes in balance}

Table 7 demonstrates the descriptive statistics regarding the balance. In the pretest of balance, the WBV group showed $27.44 \pm$ 20.42 before the bowling event and $26.00 \pm 16.93$ after the bowling event whereas the control group showed $18.33 \pm 9.33$ before the bowling event which was increased to $18.67 \pm 6.96$ after the bowling event. In the posttest, the WBV group showed $98.22 \pm 51.28$ before the bowling event and 101.67 \pm 53.08 after the bowling event whereas the control group showed 17.00 \pm 9.58 before the bowling event which was increased to $19.44 \pm 10.67$ after the bowling event.

Table 6. The difference of extensor peak torque between groups tested by repeated measured analysis of variance

\begin{tabular}{|c|c|c|c|c|c|c|c|c|}
\hline \multicolumn{4}{|l|}{ Source } & SS & DF & MS & $F$ & $P$-value \\
\hline \multirow[t]{9}{*}{ Right } & \multirow[t]{3}{*}{ Within } & \multicolumn{2}{|l|}{ Time } & $1,843.66$ & 3 & 614.55 & 0.53 & 0.661 \\
\hline & & \multicolumn{2}{|l|}{ Time $\times$ group } & $17,366.27$ & 3 & $5,788.75$ & 5.03 & $0.004^{* *}$ \\
\hline & & \multicolumn{2}{|l|}{ Error } & $55,154.55$ & 48 & $1,149.05$ & - & - \\
\hline & \multirow[t]{2}{*}{ Between } & \multicolumn{2}{|l|}{ Group } & 445.01 & 1 & 445.01 & 0.26 & 0.612 \\
\hline & & \multicolumn{2}{|l|}{ Error } & $24,907.50$ & 15 & $1,660.50$ & - & - \\
\hline & \multirow[t]{4}{*}{ Contrast } & \multirow[t]{4}{*}{ Time $\times$ group } & $1: 2$ & 910.22 & 1 & 910.22 & 0.42 & 0.526 \\
\hline & & & $1: 3$ & $22,401.38$ & 1 & $22,401.38$ & 12.05 & $0.003^{* *}$ \\
\hline & & & $2: 4$ & $12,116.05$ & 1 & $12,116.05$ & 3.15 & 0.095 \\
\hline & & & $3: 4$ & 88.88 & 1 & 88.88 & 0.05 & 0.812 \\
\hline \multirow[t]{9}{*}{ Left } & \multirow[t]{3}{*}{ Within } & \multicolumn{2}{|l|}{ Time } & $3,378.94$ & 3 & $1,126.31$ & 1.12 & 0.350 \\
\hline & & \multicolumn{2}{|l|}{ Time $\times$ group } & $14,721.88$ & 3 & 4,907.29 & 4.87 & $0.005^{* *}$ \\
\hline & & \multicolumn{2}{|l|}{ Error } & $48,285.16$ & 48 & $1,005.94$ & - & - \\
\hline & \multirow[t]{2}{*}{ Between } & \multicolumn{2}{|l|}{ Group } & $1,530.88$ & 1 & $1,530.88$ & 0.78 & 0.390 \\
\hline & & \multicolumn{2}{|l|}{ Error } & $29,402.47$ & 15 & $1,960.16$ & - & - \\
\hline & \multirow[t]{4}{*}{ Contrast } & \multirow[t]{4}{*}{ Time $\times$ group } & $1: 2$ & 544.50 & 1 & 544.50 & 0.29 & 0.594 \\
\hline & & & $1: 3$ & $18,753.38$ & 1 & $18,753.38$ & 8.60 & $0.010^{*}$ \\
\hline & & & $2: 4$ & 10,609.38 & 1 & 10,609.38 & 3.99 & 0.063 \\
\hline & & & $3: 4$ & 112.50 & 1 & 112.50 & 0.09 & 0.759 \\
\hline
\end{tabular}

SS, Sum of squares; DF, Degree of freedom; MS, Mean of squares.

1, pre-pre: pre-test before bowling game. 2, pre-post: pre-test after bowling game. 3, post-pre: post-test before bowling game. 4, post-post: post-test after bowling game. ${ }^{*} P<0.05$. ${ }^{* *} P<0.01$.

Table 7. The change of balance at descriptive statistics and estimate of covariate (unit: sec)

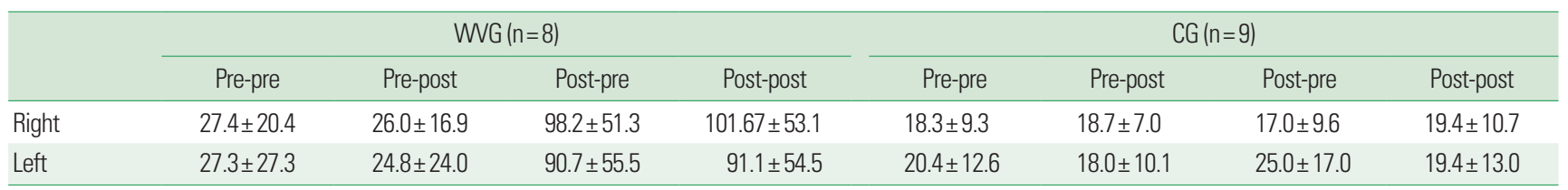

Values are presented as mean \pm standard deviation. WVG, whole body vibration group; CG, control group.

Pre-pre, pre-test before bowling game; Pre-post, pre-test after bowling game; Post-pre, post-test before bowling game; Post-post, pre-test after bowling game. 
Table 8. The difference of accuracy between groups tested by repeated measured analysis of variance

\begin{tabular}{|c|c|c|c|c|c|c|c|c|}
\hline Source & & & & SS & DF & MS & $F$ & $P$-value \\
\hline \multirow[t]{9}{*}{ Right } & \multirow[t]{3}{*}{ Within } & \multicolumn{2}{|l|}{ Time } & $24,024.8$ & 3 & $8,008.3$ & 21.4 & $0.000^{* * *}$ \\
\hline & & \multicolumn{2}{|l|}{ Time $\times$ group } & $24,319.5$ & 3 & $8,106.5$ & 21.7 & $0.000^{* * *}$ \\
\hline & & \multicolumn{2}{|l|}{ Error } & $17,951.9$ & 48 & 374.0 & & \\
\hline & \multirow[t]{2}{*}{ Between } & \multicolumn{2}{|l|}{ Group } & $9,101.3$ & 1 & $9,101.3$ & 17.1 & $0.001^{* *}$ \\
\hline & & \multicolumn{2}{|l|}{ Error } & $12,033.0$ & 15 & 802.2 & & \\
\hline & \multirow[t]{4}{*}{ Contrast } & \multirow[t]{4}{*}{ Time $\times$ group } & $1: 2$ & 14.2 & 1 & 14.2 & 0.1 & 0.734 \\
\hline & & & $1: 3$ & $23,400.1$ & 1 & $23,400.1$ & 22.3 & $0.000^{* * *}$ \\
\hline & & & $2: 4$ & $25,237.6$ & 1 & $25,237.6$ & 24.8 & $0.000^{* * *}$ \\
\hline & & & $3: 4$ & 4.5 & 1 & 4.5 & 0.0 & 0.883 \\
\hline \multirow[t]{9}{*}{ Left } & \multirow[t]{3}{*}{ Within } & \multicolumn{2}{|l|}{ Time } & $20,821.2$ & 3 & $6,940.4$ & 24.90 & $0.000^{* * *}$ \\
\hline & & \multicolumn{2}{|l|}{ Time $\times$ group } & $17,286.2$ & 3 & $5,762.1$ & 20.67 & $0.000^{* * *}$ \\
\hline & & \multicolumn{2}{|l|}{ Error } & $13,377.9$ & 48 & 278.7 & & \\
\hline & \multirow[t]{2}{*}{ Between } & \multicolumn{2}{|l|}{ Group } & $6,412.8$ & 1 & $6,412.8$ & 8.0 & $0.012^{*}$ \\
\hline & & \multicolumn{2}{|l|}{ Error } & $7,964.0$ & 15 & 530.9 & & \\
\hline & \multirow[t]{4}{*}{ Contrast } & \multirow[t]{4}{*}{ Time $\times$ group } & $1: 2$ & 0.1 & 1 & 0.1 & 0 & 0.984 \\
\hline & & & $1: 3$ & $15,546.7$ & 1 & $15,546.7$ & 21.0 & $0.000^{* * *}$ \\
\hline & & & $2: 4$ & $18,947.6$ & 1 & $18,947.6$ & 27.2 & $0.000^{* * *}$ \\
\hline & & & $3: 4$ & 162.0 & 1 & 162.0 & 0.5 & 0.478 \\
\hline
\end{tabular}

SS, Sum of squares; DF, Degree of freedom; MS, Mean of squares.

1, pre-pre: pre-test before bowling game. 2, pre-post: pre-test after bowling game. 3, post-pre: post-test before bowling game. 4, post-post: post-test after bowling game. ${ }^{*} P<0.05$. ${ }^{*} P<0.01 .{ }^{* *} P<0.001$.

In the pretest of left side balance, the WBV group showed $27.33 \pm 27.25$ before the bowling event and $24.78 \pm 24.02$ after the bowling event whereas the control group showed $20.44 \pm$ 12.60 before the bowling event which was reduced to $18.00 \pm$ 10.11 after the bowling event. In the posttest, the WBV group showed $90.67 \pm 55.49$ before the bowling event and $91.11 \pm 54.53$ after the bowling event whereas the control group showed $25.00 \pm$ 16.96 before the bowling event which was reduced to $19.44 \pm$ 13.00 after the bowling event.

Table 8 demonstrates the result of repeated measured ANOVA to examine the changes in balance.

The results of repeated measured ANOVA for right side balance showed significant difference in the main effects, timing and interactions ( $F=21.67, P<0.001)$. As a result of individual comparison, there was significant difference between before the bowling event during the pretest and before the bowling event during the posttest as well as after the bowling event during the pretest and after the bowling event during the posttest $(F=22.25, P<0.001$; $F=24.78 P<0.001$ ).

In terms of left side balance, there was significant difference in the main effects, timing and interactions $(F=24.90, P<0.001$; $F=20.67, P<0.001)$. As a result of individual comparison, there was significant difference between before the bowling event during the pretest and before the bowling event during the posttest as well as after the bowling event during the pretest and after the bowling event during the posttest $(F=21.04, P<0.001 ; F=27.21$, $P<0.001)$

\section{DISCUSSION}

Increasing number of studies have reported the positive impact of WBV exercise on morphological and functional development of muscular fibers (Miyazaki, 2000; Rittweger, 2010). In particular, in advanced countries including Europe where vibration is classified as an exercise intervention, a number of studies have examined physical strength improvement of athletes as a means to improve their performance in the field of sports (Bosco et al., 1999; Cochrane and Stannard, 2005) whereas there are no studies on bowling players. In this sense, this research is focused on the impact of WBV exercise on truncus, lower-limb strength and balance of bowling players who are registered in Korea Bowling Association.

First, I used isokinetic machine to measure the strength of truncus and lower-limb after WBV exercise at $60 \%$ sec. The results showed no significant difference between groups in their maximum rotatory force of flexor but there was significant difference in mea- 
surement timing. As a result of individual comparison, there was significant difference in before and after the WBV exercise in advance to the bowling event as well as in before and after the WBV exercise followed by the bowling event. In addition, although the maximum rotatory force in extensor of truncus did not show significant difference in the measurement timing but individual comparison within the groups showed significant difference in after the bowling event during the pretest and posttest. These results indicate that WBV exercise is effective for improving the truncus strength of bowling players. However, it is assumed that the reason there was no difference between groups in terms of rotatory force in flexor and extensor of truncus is that research subjects were professional and college bowling players who have more than 10 years of athletic career.

Among the previous studies on WBV exercise, relatively fewer studies have examined its impact on truncus strength than those which have examined its impact on lower-limb strength. Truncus strength enables effective movement of lower-limb and helps prevention of injuries (Krabak and Kennedy, 2008; Verhagen et al., 2004). In particular, Myer et al. (2008) reported that truncus strength is the most important factor for maintaining the body stability, which in turn enables free movement of upper and lower-limb. These previous studies indicate the importance of truncus strength but there is a dearth of studies on WBV. Therefore, it would be meaningful to verify the effectiveness of WBV exercise on bowling players' truncus strength. The findings from Rittweger (2010) support the results of this study by proving the positive impact of WBV exercise on back pain patients' flexor and extensor strength.

A bowling player should be able to throw a 14-16 pound ball consistently by series of sliding on a short distance of lane. Therefore, reinforcement of lower-limb strength is an important factor which affects the performance. Wirth et al. (2011) mentioned that reinforced lower-limb strength serves an important function by effectively controlling the center of gravity. In this sense, I examined the maximum rotatory force of left and right flexor and extensor in lower-limb strength by conducting WBV exercise on bowling players. The results showed significant difference in measurement timing between groups in terms of both left and right side. The results of individual comparison within the groups showed significant difference in before and after the WBV exercise in advance to the bowling event as well as in before and after the WBV exercise followed by the bowling event. Although the maximum rotatory force of extensor did not show significant difference in the measurement timing but individual comparison within the groups showed significant difference in before and after the WBV exercise in advance to the bowling event.

These results are similar to those of Mahieu et al. (2006) who reported significant difference in isokinetic muscular strength after conducting 6 weeks of WBV exercise in squatting position for Belgian junior ski players. Also, the results are supported by Krabak and Kennedy (2008) who reported significant improvement in lower-limb strength by applying WBV exercise in squatting position for female volleyball players and also corroborated by the findings of Cochrane and Stannard (2005) who reported significant improvement in lower-limb strength and counter movement jump (CMJ) after conducting diverse types of WBV exercise including the squatting position for female hockey players. Bosco et al. (2000) reported significant improvement in lower-limb strength by conducting WBV exercise in squatting position for healthy adult males. Therefore, the findings of this research support the argument that improvement in muscular strength followed by WBV exercise is due to reinforced cocontraction of synergist muscles by increasing simultaneous activation of motor nerves, which in turn causing further activation of the nerve system. For this research, I referred to previous studies and applied more suitable positions for bowling players including the squatting position on the WBV exercise foothold. Future studies should focus on multilateral aspects when applying the WBV exercise such as length of athletic career, gender, age group, etc. and cover increased number of players.

Bowling is a game to throw a ball towards 10 pins at 18 -m distance and requires high level of concentration and balance in order to completely knock down the pins (Devan and Tanaka, 2007). Therefore, I examined the impact of WBV exercise on the balance, which is an important factor in bowling performance. However, previous studies on the impact of WBV exercise on balance were mostly focused on the elderly and patients (Gusi et al., 2006; Verschueren et al., 2004) and there were almost no studies conducted on athletes. Balance can be divided into static balance which is a capability to stand still on a fixed surface and dynamic balance which is a capability to control the position without falling down while moving the body (Vuillerme et al., 2008). In this research, I examined the static balance which is the capability of bowling players to swing steadily during the release.

The research results showed significant difference between the groups and in measurement timing in terms of left and right balance. The results of individual comparison within the groups for right side showed significant difference in before and after WBV exercise in advance to the bowling event whereas the left side 
showed significant difference in before and after WBV exercise in advance to as well as followed by the bowling event. These results are similar to those of Torvinen et al. (2002) who reported 15.7\% of significant difference in balance by conducting 8 weeks of WBV exercise on 60 healthy adults. Keays et al. (2003) mentioned that reinforced lower-limb strength is an important factor to efficiently control the center of gravity and serves an important role in improving the balance and stability by stabilizing the knees during walking. Verschueren et al. (2004) reported that 6 months of WBV exercise on 70 menopausal females brought significant difference in their static balance. Therefore, the fact that there was significant difference in balance in terms of groups and measurement timing is due to activation of core muscles through reinforced truncus and lower-limb strength.

In particular, one notable finding of this research is that there was significant difference in physical factors between the bowling event in advance to the WBV exercise and the bowling event after the WBV exercise. This finding indicates that WBV exercise brought positive effects on muscular functions and balance even after the $3 \mathrm{hr}$ of bowling games. In general, Korean bowling players do not have resting phase and participate in bowling events every month thus loss in physical strength and small injuries may have largely negative impact on performance. Furthermore, considering the risk of injuries followed by existing training methods for improving muscular functions, WBV exercise is an efficient method to safely maximize physical strength within a short period of time.

\section{CONFLICT OF INTEREST}

No potential conflict of interest relevant to this article was reported.

\section{REFERENCES}

Abercromby AF, Amonette WE, Layne CS, McFarlin BK, Hinman MR, Paloski WH. Vibration exposure and biodynamic responses during whole-body vibration training. Med Sci Sports Exerc 2007;39:17941800.

Bosco C, Colli R, Introini E, Cardinale M, Tsarpela O, Madella A, Tihanyi J, Viru A. Adaptive responses of human skeletal muscle to vibration exposure. Clin Physiol 1999;19:183-187.

Bosco C, Iacovelli M, Tsarpela O, Cardinale M, Bonifazi M, Tihanyi J, Viru M, De Lorenzo A, Viru A. Hormonal responses to whole-body vibration in men. Eur J Appl Physiol 2000;81:449-454.
Cochrane DJ, Stannard SR. Acute whole body vibration training increases vertical jump and flexibility performance in elite female field hockey players. Br J Sports Med 2005;39:860-865.

Delecluse C, Roelants M, Verschueren S. Strength increase after wholebody vibration compared with resistance training. Med Sci Sports Exerc 2003;35:1033-1041.

DeVan AE, Tanaka H. Declines in ten-pin bowling performance with advancing age. Age Ageing 2007;36:693-694.

Gusi N, Raimundo A, Leal A. Low-frequency vibratory exercise reduces the risk of bone fracture more than walking: a randomized controlled trial. BMC Musculoskelet Disord 2006;7:92.

Jepsen DB, Thomsen K, Hansen S, Jørgensen NR, Masud T, Ryg J. Effect of whole-body vibration exercise in preventing falls and fractures: a systematic review and meta-analysis. BMJ Open 2017;7:e018342.

Keays SL, Bullock-Saxton JE, Newcombe P, Keays AC. The relationship between knee strength and functional stability before and after anterior cruciate ligament reconstruction. J Orthop Res 2003;21:231-237.

Krabak B, Kennedy DJ. Functional rehabilitation of lumbar spine injuries in the athlete. Sports Med Arthrosc Rev 2008;16:47-54.

Mahieu NN, Witvrouw E, Van de Voorde D, Michilsens D, Arbyn V, Van den Broecke W. Improving strength and postural control in young skiers: whole-body vibration versus equivalent resistance training. J Athl Train 2006;41:286-293.

Miyazaki Y. Adverse effects of whole-body vibration on gastric motility. Kurume Med J 2000;47:79-86.

Myer GD, Chu DA, Brent JL, Hewett TE. Trunk and hip control neuromuscular training for the prevention of knee joint injury. Clin Sports Med 2008;27:425-448.

Rittweger J. Vibration as an exercise modality: how it may work, and what its potential might be. Eur J Appl Physiol 2010;108:877-904.

Torvinen S, Kannus P, Sievänen H, Järvinen TA, Pasanen M, Kontulainen S, Järvinen TL, Järvinen M, Oja P, Vuori I. Effect of four-month vertical whole body vibration on performance and balance. Med Sci Sports Exerc 2002;34:1523-1528.

Verhagen E, van der Beek A, Twisk J, Bouter L, Bahr R, van Mechelen W. The effect of a proprioceptive balance board training program for the prevention of ankle sprains: a prospective controlled trial. Am J Sports Med 2004;32:1385-1393.

Verschueren SM, Roelants M, Delecluse C, Swinnen S, Vanderschueren D, Boonen S. Effect of 6-month whole body vibration training on hip density, muscle strength, and postural control in postmenopausal women: a randomized controlled pilot study. J Bone Miner Res 2004;19: 352-359.

Vuillerme N, Chenu O, Pinsault N, Fleury A, Demongeot J, Payan Y. Can a plantar pressure-based tongue-placed electrotactile biofeedback im- 
prove postural control under altered vestibular and neck proprioceptive conditions? Neuroscience 2008;155:291-296.

Wirth B, Zurfluh S, Müller R. Acute effects of whole-body vibration on trunk muscles in young healthy adults. J Electromyogr Kinesiol 2011; 21:450-457. 